\title{
Primary Prostatic Diffuse Large B-Cell Lymphoma: A Case Report and Literature Review
}

\author{
Samia Yasmeen ${ }^{1}$, Waqas Ahmad², Omer Waqas³ ${ }^{3}$ Abdul Hameed 4
}

${ }^{1}$ Department of Medical Oncology, Prince Faisal Cancer Center, Buraidah, Saudi Arabia, ${ }^{2}$ Department of Radiology, Chelsea and Westminster NHS Trust, London, United Kingdom, ${ }^{3}$ Department of Pathology, Ittefaq Hospital (Trust), Lahore, Pakistan, “Department of Hematology/Oncology, Ittefaq Hospital (Trust), Lahore, Pakistan

Received: 15 November 2021/Acceptance: 16 December 2021

\section{Open access}

\section{Correspondence:}

Samia Yasmeen, Prince Faisal

Cancer Center, 7505 King

Abdullah Rd., An Naziyah,

Buraydah 52366, Saudi Arabia.

E-mail: drsamihfh@gmail.com

Citation: Yasmeen S, Ahmad W, Waqas $\mathrm{O}$, Hameed A. Primary Prostatic Diffuse Large B-Cell Lymphoma: A Case Report and Literature Review. J Cancer Allied Spec [Internet]. 2022 Jan 31;8(1).e1002957.

https://doi.org/10.37029/jcas. v8i1.439

Copyright: (c) 2022 Yasmeen, et al.This is an open access article distributed under the terms of the Creative Commons Attribution License, which permits unrestricted use, distribution, and reproduction in any medium, provided the original author and source are credited.

Funding: The authors received no financial support for the research, authorship and/or publication of this article.

\section{Competing interest: Nil.}

\section{Introduction}

Primary lymphoma of the prostate is extremely rare, accounting approximately $0.2-0.8 \%$ of extra nodal lymphoma and $<0.1 \%$ of all prostate cancers. ${ }^{[1]}$ The most common histological types of prostatic nonHodgkin's lymphomas (NHLs) are diffuse large B-cell lymphoma (DLBCL). ${ }^{[2]}$ The mean age at diagnosis

\begin{abstract}
Introduction: Primary lymphomas of the prostate are globally rare, representing $<0.1 \%$ of all prostatic neoplasms. Their rarity and non-specific symptomatology at presentation usually prompt a clinical diagnosis of benign prostatic hyperplasia or chronic prostatitis, leading to significant delay in diagnosis. Case Description: A 32-year-old man presented to our clinic with complaints of difficult urination and perineal pain. An enlarged, hard and nodular prostate was palpable on digital rectal examination. Needle biopsy of the prostate was performed, which revealed diffuse large B-cell non-Hodgkin's lymphoma by immunohistochemical studies. Computed tomography (CT) scan showed a large pelvic mass arising from prostate encasing ureters with bilateral hydronephroureter. No abnormal finding was seen on abdominal CT scan and bone marrow biopsy. Therefore, the disease was classified into the clinical stage IAXE according to the Ann Arbor's criteria. The patient achieved complete response to six cycles of rituximab plus cyclophosphamide, doxorubicin, vincristine and prednisone chemotherapy with the central nervous system prophylaxis. He remained disease free, until 36 months after the end of chemotherapy. Practical Implications: According to the literature, the treatment and prognosis of primary lymphoma of the prostate are the same as that of other nodal lymphomas. The rituximab-based regimen should be considered in the management of prostatic diffuse large B-cell lymphoma.
\end{abstract}

Key words: Diffuse large B-cell lymphoma, primary lymphomas, prostate is in the sixth to a seventh decade for both primary and secondary prostatic lymphomas. ${ }^{[3]}$ Clinical presentation varies with symptoms of urinary obstruction and renal failure in some patients. In contrast, others may present with haematuria, pain and rarely B symptoms (absence of fever, night sweats and weight loss). ${ }^{[2]}$ Imaging modalities, including computed tomography (CT), transrectal 
ultrasonogram, positron emission tomography (PET)/CT and magnetic resonance imaging (MRI), are helpful to reach the diagnosis. Pathological and immunohistochemical examination can make the subsequent final diagnosis of samples obtained by prostate biopsy. ${ }^{[4]}$ The standard treatment of choice is rituximab plus cyclophosphamide, doxorubicin, vincristine and prednisone chemotherapy (R-CHOP). ${ }^{[5]}$ Because of the rarity of the disease, the prognosis of primary prostatic lymphoma is not clear. It remains uncertain whether the prognosis of prostatic lymphoma is significantly worse or equivalent to nodal lymphoma. ${ }^{[1]}$

\section{Case Description}

A 32-year-old male presented to our institution with difficulty in urination and perineal pain suggestive of urinary obstruction for the past 2 months. He had no relevant medical history. At the first presentation, his performance status was equal to zero.

\section{Diagnosis and Management}

Digital rectal examination (DRE) showed an enlarged, firm and nodular prostate weighing $50 \mathrm{~g}$. Ultrasonography prostate showed voluminous prostate and bilateral hydronephrosis with a serum creatinine of $8 \mathrm{mg} / \mathrm{dl}$ (normal $0-1 \mathrm{mg} / \mathrm{dl}$ ). The serum prostate-specific antigen (PSA) was negative, $0.5 \mathrm{ng} / \mathrm{ml}$ (normal $<4 \mathrm{ng} / \mathrm{ml}$ ). Histological and immunohistochemical studies of needle biopsy of prostate tissue by transurethral resection showed diffuse large B-cell lymphoma with most of the cells positive for cluster differentiation - 20 and 10 and leucocytes common antigen with $\mathrm{Ki}-67$ of $50 \%$ in tumour cells [Figures 1-4].

The CT scan [Figure 5] demonstrated a large pelvic mass arising from the prostate and measuring about $146 \mathrm{~mm}$ in maximum dimensions. This mass was encasing bilateral lower ureters and was invading the posterior wall of the bladder. The mass was inseparable from the sigmoid colon and rectum, and the rectum was being pushed posterior as well. Bilateral moderate hydronephroureter with percutaneous nephrostomy (PCN) in situ in the left kidney was also seen. No evidence

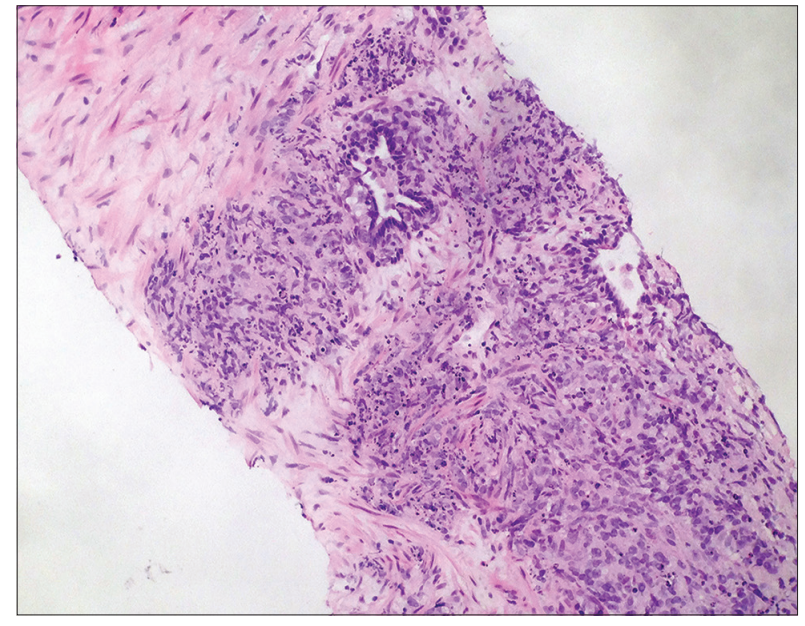

Figure 1: Prostatic core biopsy showing diffuse infiltrate of discohesive cells, cells are medium to large sized with abundant cytoplasm, vesicular nuclei and distinct nucleoli. No gland formation is present

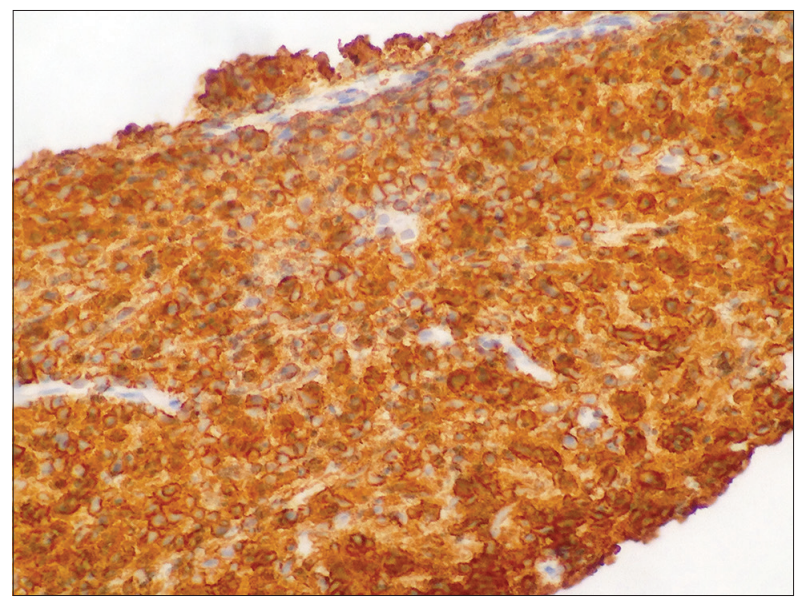

Figure 2: Prostatic core biopsy showing positive staining for cluster differentiation 45 (CD 45) (leucocytes common antigen)

of distant metastasis in the lungs and abdomen was seen. His bone marrow biopsy showed no abnormalities, and erythrocytes sedimentation rate was 45 with lactate dehydrogenase (LDH) $725 \mathrm{mg} / \mathrm{dl}$. The patient was staged as Stage I-AXE with the absence of B-symptoms including fever, weight loss and night sweats ( $A)$, bulky disease more than $10 \mathrm{~cm}$ in largest diameter $(X)$ and involvement of single, extranodal site continuous or proximal to known nodal site (E) according to the Ann Arbor classification system. Before 


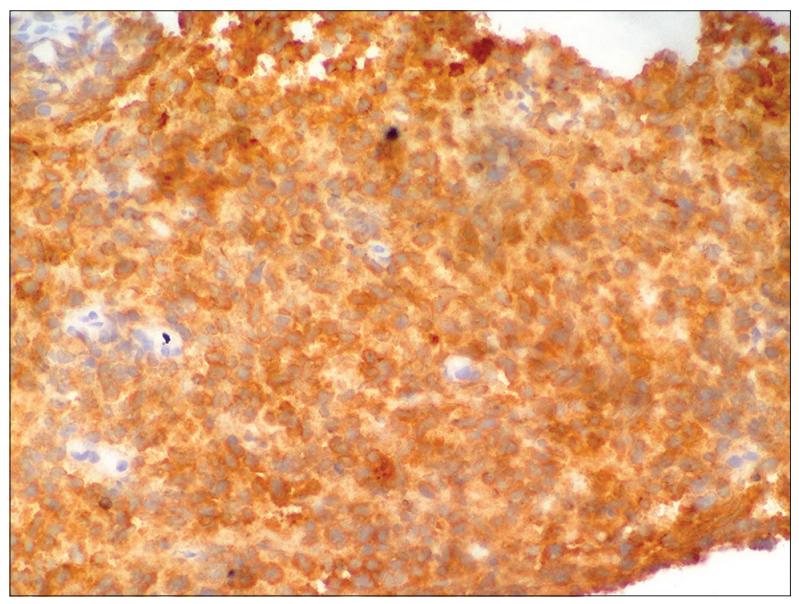

Figure 3: Prostatic core biopsy showing positive staining for cluster differentiation 20 (CD 20)

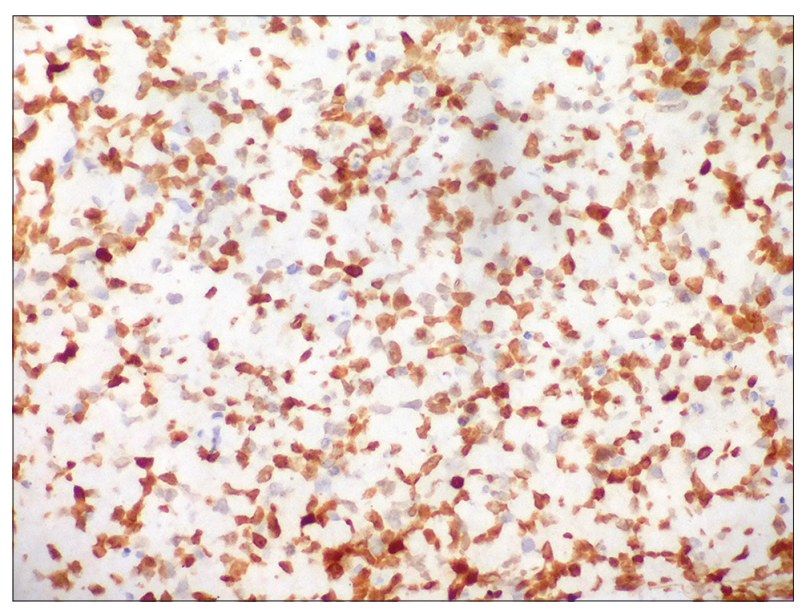

Figure 4: Prostatic core biopsy showing positive staining for cluster differentiation 10 (CD 10)

starting therapy, the patient was managed on lines of obstructive uropathy and left-sided PCN tube was also inserted. The patient received six cycles of chemotherapy (R-CHOP-IT) containing rituximab $\left(375 / 50 \mathrm{ml} / \mathrm{m}^{2}\right)$, cyclophosphamide $\left(750 \mathrm{mg} / \mathrm{m}^{2}\right)$, doxorubicin $\left(50 \mathrm{mg} / \mathrm{m}^{2}\right)$ and vincristine $\left(1.4 \mathrm{mg} / \mathrm{m}_{2}\right)$ on day 1 and prednisolone (100 mg) on days 1-5. He was given intrathecal methotrexate $(12 \mathrm{mg})$ on day 2 of each cycle. In addition, he was also given two cycles of high dose of methotrexate $\left(3500 \mathrm{mg} / \mathrm{m}^{2}\right)$ after cycle 2 and cycle 5 of chemotherapy.

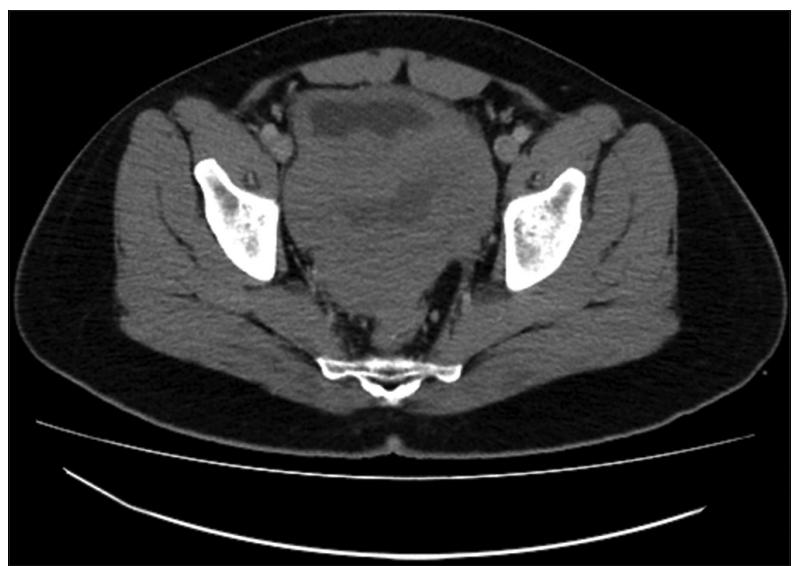

Figure 5: Pre-treatment axial computed tomography scan image showing large heterogeneous mass (prostate) with internal necrosis causing mass effect on bladder and rectum

The end of treatment CT scan [Figure 6] and PET scan [Figure 7] done after six cycles of chemotherapy showed a complete morphological and metabolic response. The patient was offered consolidative radiotherapy to prostate that he had refused. The patient remained disease free until after 36 months of treatment.

\section{Discussion}

Among all prostatic malignancies, adenocarcinoma is predominant, representing almost $90 \%$ of the cases. In contrast, among other histological subtypes, primary prostatic lymphomas comprise only about $0.1 \%$ of all prostatic neoplasms. ${ }^{[6]}$ The most common histological subtypes of prostatic NHLs are DLBCL and B-cell chronic lymphocytic leukaemia. Other types include marginal zone, mantle cell, follicular and Burkitt's lymphomas. ${ }^{[3]}$ About 165 cases of primary and secondary prostatic lymphomas have been mentioned in the literature where NHLs represent the major entity. ${ }^{[2]}$

The most of the cases of prostatic lymphoma usually occur in older men with a median age of about 62 years. However, disease occurrence in the younger population, as young as 29 years old, has been reported. ${ }^{[7]}$ 


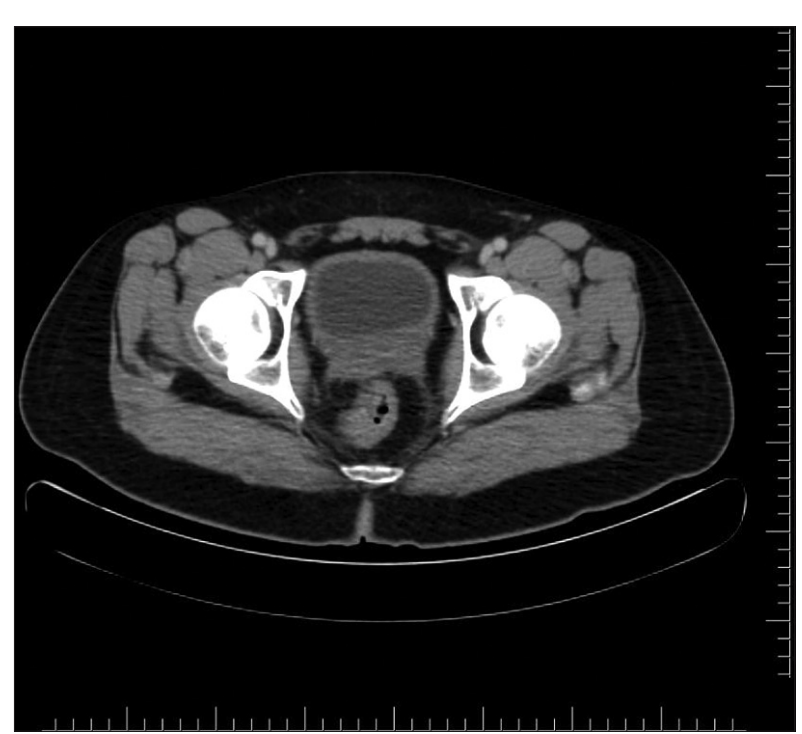

Figure 6: Post-treatment axial computed tomography image showing significant interval reduction in primary disease

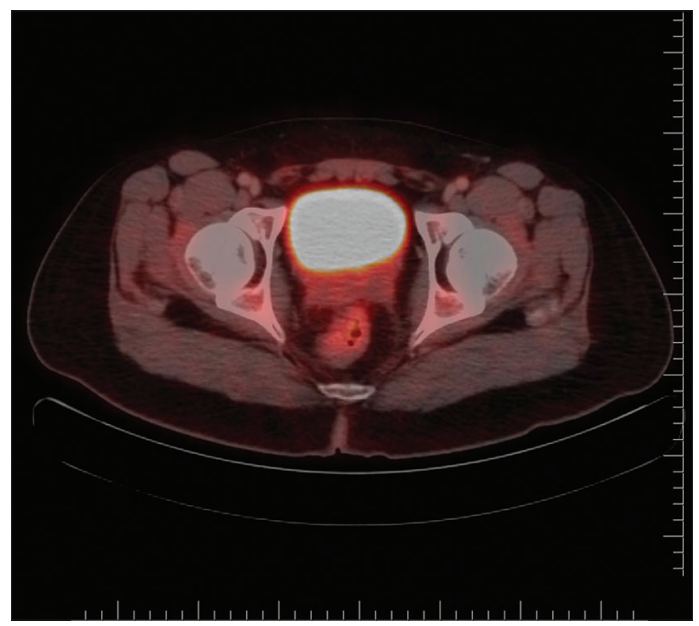

Figure 7: Post-treatment positron emission tomography image showing significant interval reduction at the primary site without any avid metabolic disease correlating with complete metabolic response

Bostwick et al. defined criteria for the diagnosis of primary prostatic lymphoma. According to these criteria, a prostate tumour is labelled as primary $\mathrm{NHL}$ when there is no lymph node, liver, spleen or bone marrow involvement; major presenting symptoms involve the prostate and adjacent structures; and when there is at least 1-month progression-free interval from diagnosis. ${ }^{[8]}$ In the present case, the main bulk of disease was confined to the prostate, and it met the defined criteria.

The most of the patients present with the lower urinary tract obstruction symptoms, such as increased urinary frequency, urgency, haematuria or acute retention, sometimes leading to renal failure. This condition is often mistaken for benign hyperplasia or chronic prostatitis due to nonspecific symptoms, resulting in delayed diagnosis and treatment. Systemic symptoms are usually absent with a normal PSA value. ${ }^{[7]}$ Our patient presented with symptoms of urinary obstruction with no B-symptoms, firm prostate weighing $50 \mathrm{~g}$ on DRE and normal PSA.

The diagnostic approach includes medical history, physical examination including DRE, transrectal ultrasound, computed topography (CT) or MRI scans and a prostate biopsy with complete histological examination. ${ }^{[2]}$ In the present case, the CT revealed that similar radiological features as were mentioned in published cases of $\mathrm{NH}$, such as enlargement of the prostate with no evidence of distant metastasis, and diagnosis was finally confirmed by pathological and immunohistochemical examination.

There are no specific guidelines regarding the optimal treatment of prostatic lymphoma due to the rare nature of this disease entity. Different treatment modalities include radical prostatectomy, chemotherapy, radiotherapy or concurrent chemoradiotherapy. ${ }^{[2]}$ The mainstay of therapy is R-CHOP for most early-stage diseases. Earlier series report a poor prognosis for prostatic lymphomas, but the present literature has shown better progression-free survival with combined chemotherapy (R-CHOP). ${ }^{[7]} A$ recent review of 23 cases showed that patients responded well to chemotherapy and could be cured if the primary prostatic lymphoma was confined to the prostatic region. ${ }^{[9]}$

Our patient in the present study was diagnosed early and treated appropriately with R-CHOP chemotherapy regimen along with primary central 
nervous system (CNS) prophylaxis including intrathecal and intravenous methotrexate, resulting in excellent results and achieving complete metabolic response after four cycles. As no clear consensus exists regarding the treatment of primary prostatic lymphoma, CNS prophylaxis was given based on the extranodal site of disease and high serum LDH. The patient was followed for 36 months after treatment completion and currently remains in good health and in remission. To obtain long-term follow-up, further observation is required.

Because of its rarity, knowledge of this disease, consideration in differential diagnosis and a thorough histological examination are the only safe way to avoid diagnostic mistakes resulting in timely treatment and excellent results.

\section{References}

1. Lahyani M, Jabbour Y, Bakloul F, Karmouni T, Elkhader K, Koutani A, et al. Primary malignant lymphoma of the prostate: Report of a case achieving complete response chemotherapy. Elixir Urol 2015;86:35106-7.

2. Petrakis G, Koletsa T, Karavasilis V, Rallis G, Bobos M, Karkavelas G, et al. Primary prostatic lymphoma with components of both diffuse large B-cell lymphoma (DLBCL) and MALT lymphoma. Hippokratia 2012;16):86.

3. Warrick JI, Owens SR, Tomlins SA. Diffuse large B-cell lymphoma of the prostate. Arch Pathol Lab Med 2014;138:1286-9.

4. Hu S, Wang Y, Yang L, Yi L, Nian Y. Primary nonHodgkin's lymphoma of the prostate with intractable hematuria: A case report and review of the literature. Oncol Lett 2015;9:1187-90.

5. Pan B, Han JK, Wang SC, Xu A. Positron emission tomography/computerized tomography in the evaluation of primary non-Hodgkin's lymphoma of prostate. World J Gastroenterol 2013;19: 6699-702.

6. Taleb A, Ismaili N, Belbaraka R, Bensouda A, Elghissassi I, Elmesbahi $O$, et al. Primary lymphoma of the prostate treated with rituximab-based chemotherapy: A case report and review of the literature. Cases J 2009;2:8875.

7. Kakkar A, Rajeshwari M, Bhethanabhotla S, Kaur K, Jain D, Gogia A, et al. Primary diffuse large B-cell lymphoma of the prostate: A report of two cases with diagnostic considerations. J Cancer Res Ther 2015;11:977-9.

8. Bostwick DG, Iczkowski KA, Amin MB, Discigil G, Osborne B. Malignant lymphoma involving the prostate. Cancer 1998;83:732-8.

9. Antunes AA, Dall'Oglio M, Srougi M. Primary lymphoma of the prostate: A rare cause of urinary obstruction. Int Braz J Urol 2004;30:410-2.

\section{Authors' Contributions}

Conceived and designed the analysis: $\mathrm{SY}$ and $\mathrm{AH}$. Collected the data: SY, WA and OW. Contributed data or analysis tools: SY, WA and OW. Performed the analysis: SY and $\mathrm{AH}$. Wrote the paper: $\mathrm{SY}$ and $\mathrm{AH}$. 